\title{
Commentary
}

\section{CKD Express (C) - A New IT-Software Proposed for a Paradigm Change in CKD Care}

\author{
Macaulay A.C. Onuigbo*
}

College of Medicine, Mayo Clinic, Rochester, MN, USA

Department of Nephrology, Mayo Clinic Health System Eau Claire, 1221 Whipple Street, Eau Claire, WI 54702, USA

In an online MBA Class, under the auspices of the University of Wisconsin Consortium, Wisconsin, USA, the first author, who would be completing an MBA in the Spring of 2012, together with a group of three fellow MBA students have proposed the development of an IT-based System called the CKD Express (C) to enable a better, more efficient, more effective and cost-saving CKD care model [1]. This was in part fulfillment of the requirements of an MBA course on the development of new products - MBA 712 [1].

Treating patients with chronic kidney disease is a growing market as over $15 \%$ of the US population (approximately over 30 million) is estimated to have CKD [2]. The MBA course group completed a market analysis with primary and secondary data analysis, a market positioning and logistics evaluation, and a complete financial budgeting process that is in fact ready to take off formally as a new product-in-development [1]. This new product (a stand-alone IT module or an add-on to existing EMR) would have the appropriate artificial intelligence (AI) [3,4], decision support system (DSS) tools [3,4], and other algorithmic components to enable a trained nurse practitioner (NP), under the supervision of a nephrologist, to track and remotely manage CKD patients by tracking serum creatinine trajectories through the IT system network $[1,3,4]$. CKD patient care would be directed and managed by the NP after an initial full history and physical examination, to continue to carry out serum creatinine tests at stipulated intervals according to the algorithms recommended by the CKD Express (C) [1]. The NP will be responsible for directing frequency of laboratory tests (serum creatinine), timing of referral to specialist nephrologists or Emergency Departments, even when such CKD patients are living in remote and far flung apart rural areas, as long as they get to carry out the stipulated tests in the specified laboratory systems and the CKD Express (C) is able to have these laboratory data imported to it via established and secure IT networks [1]. This way, nephrologists, following timely referrals would see and manage CKD patients who require their expertise as determined by recent worsening kidney function and so on. Given the fact that by current estimates

*Address correspondence to this author at the Department of Nephrology, Mayo Clinic Health System Eau Claire, 1221 Whipple Street, Eau Claire, WI 54702, USA; Tel: 715838 3891; Fax: 715838 1946;

E-mail: onuigbo.macaulay@mayo.edu about $15 \%$ of Americans have CKD [2], and whereas we do not have enough nephrologists to attend to all CKD patients anyways [2], and whereas, if truth be told, there is no overarching reason to have all CKD patients (stage III-V) necessarily see nephrologists [5-7], and whereas quite often, even over years, a significant proportion of CKD patients do actually maintain a stable kidney function [8-11], it is our submission that this new IT-based product would introduce an efficient, effective, cost-saving and convenient new CKD care model [1]. The CKD Express (C) expert IT system is currently undergoing patent application and we are therefore constrained from releasing any more technical details than we have here already. Nevertheless, we have provided access to the MBA thesis as a repository with the Editor of The Open Medical Informatics Journal for anybody who wants all the management and marketing details regarding the new product development process [1].

A population-based sampling of Wisconsin adults reveal estimated CKD prevalence rates of up to $15 \%$ and higher in several studies [2]. This would translate to over 30 million CKD patients in the USA. Despite increased calls for referral of patients with later stage CKD to be seen by nephrologists [12], it remains unclear whether the more expensive nephrology care of these CKD patients is indeed cost-effective [13]. The US healthcare system with escalating costs outstripping inflation, and consuming an ever increasing percentage of the gross domestic product (GDP) at an unsustainable rate, cannot continue with business as usual since the current system is virtually broken [14]. Furthermore, evidence continues to mount that despite increased US healthcare spending, quality outcomes are suboptimal, and care is fragmented and poorly coordinated [14]. Indeed, over the last 15 years, the US has far surpassed most countries in the developed world for total healthcare expenditures per capita $[15,16]$. In 2009 , the US spent $17.4 \%$ of GDP on healthcare, translating to $\$ 7,960$ per capita, whereas Japan spent only $8.5 \%$ of its GDP, averaging $\$ 2,878$ per capita [16]. At current rates, the healthcare bill in the US will increase from $\$ 2.5$ trillion in 2009 to over $\$ 4.6$ trillion in 2020 [17]. We must make radical paradigm changes in the way we deliver care. We submit that CKD Express $(C)$ is one such paradigm change waiting to happen [1]. This is even now more urgent and pressing, especially with the recent global financial recession and the cutbacks in government expenditures on health and social support services around the world, due to the dire economic recession and other economic stresses facing most of the world economies in 2011 [18]. 
During our new product development-related market surveys, some physicians and hospital administrators had raised concerns about resulting reduced patient visits to physicians and therefore a loss of physician productivity and therefore a fall in physician compensation [1]. Arguably, it can be unethical for specialist physicians to see CKD patients simply routinely and get paid, while not necessarily contributing significantly to the CKD patients' wellbeing [5-7]. This is one place where ethics, medicine and economics collide. In 2011, in an editorial commentary in the International Journal of Clinical Practice, we dubbed this scenario, the syndrome of 'Ethicomedicinomics' [18]. Moreover, from our surveys and market analysis, currently only a very small percentage of CKD patients even get to do blood tests or are seen by any healthcare provider [1]. By extending the reach of the medical unit to millions of currently unattended CKD patients, CKD Express (C) will indeed ultimately result in increased patient visits [1].

It is the hope that CKD Express (C) would cut down on costly and unnecessary nephrologists' referrals (5-7). CKD Express $\mathbb{C}$ would reach the unmet needs of many needing CKD patients who under the current CKD care paradigms are not even seen until quite lately, when they need RRT (1). It is our hope that this new IT-based CKD care model would reduce the cost of CKD care while improving the quality of life of CKD patients, and at the same time reduce the ESRD epidemic affecting both the US and the world in general [1]. Finally, CKD Express (C) would turn out to be a beneficial new CKD treatment program that can help the growing number of patients diagnosed with CKD receive more affordable and easier to access treatment [1]. Worldwide, there are different approaches being entertained to improve CKD outcomes and CHRONIOUS is a new web-based open, ubiquitous and adaptive Chronic Disease Management Platform for COPD and Renal Insufficiency that aims to accommodate key technological fields such as wearables, sensing systems (vital signals, environmental, activity and context-aware), sensor management techniques, intelligent multi-parametric data fusion algorithms and medical decision support systems, medical guidelines, ontologies and wireless communication networks, and advance interfaces (taking into account Human Computer Interaction factors) [19].

\section{ACKNOWLEDGEMENT}

This innovative work, the product of my MBA course completed in May 2012, is dedicated to the memory of Chigbo Eduzor $\mathrm{MD}$, an old friend and professional colleague, who just passed this last weekend, August 2012, in Awka, Anambra State, Nigeria. May his soul rest in peace.

\section{CONFLICT OF INTEREST}

The authors confirm that this article content has no conflicts of interest.

\section{REFERENCES}

[1] Venn C, Schmidt J, Hemdanie KC, Onuigbo M. CKD Express Corporation. Improving our patients' quality of life. A dissertation submitted December 15, 2011, to the Univeristy of Wisconsin Online MBA Consortium in fulfillment of the requirements for the MBA 712 - Developing New Products and Services.

[2] Shankar A, Lee KE, Klein BE, et al. Estimating glomerular filtration rate in a population-based study. Vasc Health Risk Manag 2010; 6: 619-27.

[3] Stair RM, Reynolds GW. In: Principles of Information Systems. A Managerial Approach. $9^{\text {th }}$ ed. Course Technology Boston, Massachusetts: Cengage Learning. 2010.

[4] Tan J, Payton FC. In: Adaptive Health Management Information Systems. Concepts, Cases and Practical Applications. $3^{\text {rd }}$ ed. Sudbury, Massachusetts: Jones and Bartlett 2010.

[5] Stevens LA, Levey AS. Impact of reporting estimated glomerular filtration rate: it's not just about us. Kidney Int 2009; 76(3): 245-7.

[6] Hemmelgarn BR, Zhang J, Manns BJ, et al. Alberta Kidney Disease Network. Nephrology visits and health care resource use before and after reporting estimated glomerular filtration rate. JAMA 2010; 303(12): 1151-8.

[7] Campbell KH, Smith SG, Hemmerich J, et al. Patient and provider determinants of nephrology referral in older adults with severe chronic kidney disease: a survey of provider decision making. BMC Nephrol 2011; 12: 47.

[8] Onuigbo M. The Validity of current CKD staging paradigms revisited and disputed: a 2-year snap shot of stage iv ckd patients in a mayo clinic laboratory database: a call for process reengineering in nephrology practice. J Am Soc Nephrol 2011. [SA-PO2472]. (Abstract).

[9] Sikaneta T, Abdolell M, Taskapan H, et al. Variability in CKD stage in outpatients followed in two large renal clinics. Int Urol Nephrol 2011. [Epub ahead of print].

[10] Onuigbo MA, Onuigbo NT. Variability in CKD stage in outpatients followed in two large renal clinics: implications for CKD trials and the status of current knowledge of patterns of CKD to ESRD progression. Int Urol Nephrol 2011. [Epub ahead of print].

[11] Sikaneta T, Roscoe J, Fung J, et al. Variability in CKD stage in outpatients followed in two large renal clinics: implications for CKD trials and the status of current knowledge of patterns of CKD to ESRD progression: response to Dr. Onuigbo. Int Urol Nephrol 2011. [Epub ahead of print]

[12] Coritsidis GN, Linden E, Stern AS. The role of the primary care physician in managing early stages of chronic kidney disease. Postgrad Med 2011; 123(5): 177-85.

[13] Winkelmayer WC, Liu J, Chertow GM, Kurella TM. Predialysis nephrology care of older patients approaching end-stage renal disease. Arch Intern Med 2011; 171(15): 1371-8.

[14] Longworth DL. Accountable care organizations, the patientcentered medical home, and health care reform: What does it all mean? Cleve Clin J Med 2011; 78(9): 571-582.

[15] The Concord Coalition. Escalating Health Care Costs and the Federal Budget. April 2, 2009. Available at: http://www.concord coalition.org/files/uploaded_for_nodes/docs/Iowa_Handout_final.p df[Accessed September 12, 2011]

[16] The Henry J. Kaiser Family Foundation. Snapshots: Health Care Spending in the United States and Selected OECD Countries. April 2011. Available at: http://www.kff.org/insurance/snapshot/OECD0 42111.cfm [Accessed September 12, 2011]

[17] Centers for Medicare and Medicaid Services, 2010. National Health Expenditure Projections 2010-2020. Available at: https://www.cms.gov/NationalHealthExpendData/downloads/proj2 010.pdf. [Accessed December 20, 2011].

[18] Onuigbo M. Healthcare expenditure in the United States of America in the last year of life: where ethics, medicine and economics collide? Int J Clin Pract 2012; 66(2): 226-7.

[19] CHRONIUS Project. Partially funded by the European Commission. Available at: http://www.chronious.eu/ [Accessed March 9, 2012]. 